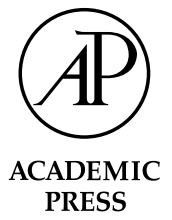

\title{
Distributed cortical networks for syntax processing: Broca's area as the common denominator
}

\author{
St. Heim, ${ }^{\mathrm{a}, *}$ B. Opitz, ${ }^{\mathrm{b}}$ and A.D. Friederici ${ }^{\mathrm{a}}$ \\ ${ }^{a}$ Max Planck Institute of Cognitive Neuroscience, P.O. Box 500 355, 04303 Leipzig, Germany \\ ${ }^{\mathrm{b}}$ Experimental Neuropsychlogy Unit, Saarland University, Saarbrücken, Germany
}

Accepted 13 February 2003

\begin{abstract}
Different types of syntactic information (word category, grammatical gender) are processed at different times during word recognition. However, it is an open issue which brain systems support these processes. In the present event-related fMRI study, subjects performed either a syntactic gender decision task on German nouns (GEN), a word category decision task (WC, nouns vs. prepositions), or a physical baseline task (BASE). Reaction times in WC were faster than in GEN, supporting earlier electrophysiological results. Relative to BASE, both syntactic tasks activated the inferior tip of BA 44 . In addition, BA 45 showed activation in GEN, whereas BA 47 was activated in WC. The imaging data indicate that the inferior portion of BA 44 together with type-specific prefrontal areas supports both initial word category related and later syntactic processes.
\end{abstract}

(c) 2003 Elsevier Science (USA). All rights reserved.

Keywords: Syntax; Gender; Word category; fMRI; Broca's area; Language comprehension

\section{Introduction}

Syntax is the backbone of every language: it comprises all types of information that assign functions to each component of an utterance and that define the relationship among these components. But there is not "syntax" per se. Rather, there are several types of syntactic information such as syntactic word category information, verb argument structure information, and syntactic gender information which may be processed differently. According to the so-called syntax-first models of comprehension only word category information such as noun, verb, article is processed during an initial phase of phrase structure building while lexically bound verb argument structure information and syntactic gender information are processed in a second phase (Frazier, 1987; Friederici, 1995; cf. Friederici, 2002, for a review).

Word category information is an essential part of every language. However, this is not true of grammatical gender: while some languages (like German and French) make use of gender information, others (like English or

\footnotetext{
${ }^{*}$ Corresponding author. Fax: +49-341-99-40-113.

E-mail address: heim@cns.mpg.de (S. Heim).
}

Japanese) do not. Within the group of languages that implement grammatical gender, the gender of the same word may differ among the languages (e.g., the car: el $\mathrm{e}_{\text {mask }}$ coche [Spanish] vs. $\mathrm{la}_{\mathrm{fem}}$ voiture [French] vs. das ${ }_{\text {neut }}$ Auto [German]). This indicates that syntactic gender, in contrast to natural gender ( $\mathrm{s} / \mathrm{he}$ ) is an idiosyncratic part of the lexical entry for a given noun in a given language.

There is electrophysiological evidence that word category information is indeed processed prior to syntactic gender information. It has been shown that the processing of a word category violation is indeed by an early left anterior negativity present around $150-200 \mathrm{~ms}$ (Hahne \& Friederici, 2002) whereas the processing of a syntactic gender violation is indicated by a somewhat later appearing left anterior negativity (300-400 ms) (Gunter, Friederici, \& Schriefers, 2000). It is an open question of whether these two types of syntactic processes are supported by the same neural systems or not. The electrophysiological data though providing evidence for these temporal separation do not offer the spatial resolution to answer this question. The goal of the present study is to investigate whether there is one central module controlling all syntactic processes or are there distinct networks for the functionally and 
temporally separable syntactic processes? Since Broca's (1861) findings on an aphasic patient with a lesion in the left inferior frontal gyrus (IFG) in Brodmann's area (BA) 44 and 45, the function of this site (also called "Broca's area") has been discussed. Although BA 45 and BA 44 are considered to constitute "Broca's area" neuromorphometric analysis have suggested a separation between the two areas (Amunts et al., 1999; Brodmann, 1909). These two areas also seem to be functionally separable as indicated by recent fMRI studies. While BA 45 as frequently been reported to be involved in semantic processes (e.g., Desmond et al., 1995; Friederici, Opitz, \& von Cramon, 2000b; Gabrieli et al., 1996; ThompsonSchill, D'Esposito, Aguirre, \& Farah, 1997), BA 44 has been found active in syntactic tasks (e.g., Friederici, Meyer, \& von Cramon, 2000a, Friederici et al., 2000b). The notion that Broca's area supports syntactic operations was put forward on the basis of neuropsychological studies (cf. Grodzinsky, 2000) and experiments on healthy subjects using neuroimaging methods. On the sentence level, there is a positive relationship between an increase in syntactic complexity of a sentence and the amount of regional cerebral blood flow in Broca's area including BA 44, 45, and even 47 (Caplan, Alpert, \& Waters, 1998, 1999; Caplan, Alpert, Waters, \& Olivieri, 2000; Just, Carpenter, Keller, Eddy, \& Thulborn, 1996; Stromswold, Caplan, Alpert, \& Rauch, 1996). The mid portion of BA 44 was shown to be activated, in particular, as a function of syntactic memory required to process syntactically complex sentences rather than as a function of syntactic complexity as such (Fiebach, Schlesewsky, \& Friederici, 2001; Grossman et al., 2002). Friederici et al. (2000a) varied the semantic and syntactic content of sentences independently and found the opercular part of Broca's area (i.e., BA 44) to be activated only in the condition in which the syntactic structure of the sentence was preserved but all content words had been replaced by pseudo-words. A similar region in the deep BA 44 was observed for pseudo-word sentences containing syntactic and morphosyntactic information (Moro et al., 2001). In the domain of single word syntax, Broca's area was involved in the processing of verbs but not nouns in a lexical decision task (Perani et al., 1999). The left BA 44/6 was activated for function words (prepositions) but not for content words (nouns) when subjects performed a detection task on subsequent synonyms (Nobre, Price, Turner, \& Friston, 1997). Since function words tend to be more abstract than content words, the authors concluded that abstract entries are harder to access and need an extra "motor" representation in the premotor cortex. However, this difference between processing function words and content words disappears if concreteness is counterbalanced between the word categories (Friederici et al., 2000b). In this latter study, subjects were presented with nouns and prepositions. One half of the items of either category was concrete, the other half abstract. In a syntactic task, subjects made a word category decision, in the semantic task they judged the word's concreteness. The result indicated that task requirements rather than word class determined activation differences in the inferior frontal cortex as a function of task: the semantic task (abstract vs. concrete) activated BA 45 whereas the syntactic task (noun vs. preposition) activated BA 44. This finding has two important implications: first, Broca's area is not the cortical localisation site of a particular word class (i.e., function words) but rather supports the underlying processes of word category decision and assignment. Second, the relatively large region called "Broca's area" can be further subdivided in functional distinct parts. It appears that the mid portion of BA 44 supports syntactic memory and the inferior portion processing of word category information and local structure building.

If it is syntactic task or processing requirements that characterises the role of the inferior tip of BA 44, one may further speculate that not only word category information but any kind of syntactic information is processed here. A language like German that offers different types of syntactic information (namely, word category and gender) is an ideal testing ground for this hypothesis. We therefore conducted an event-related fMRI study with native German speakers who had to differentiate between both kinds of information in German words.

\section{Materials and Methods}

\subsection{Participants}

Eighteen healthy right-handed subjects (age 21-29 years, nine females) participated in the experiment. They all were native German speakers and had normal or corrected to normal vision. No subject had a known history of neurological, major medical, or psychiatric disorders; none were taking medication at the time of measurement. Informed consent was obtained from all participants.

\subsection{Materials}

160 German nouns, 80 German prepositions, and 80 consonant letter strings served as experimental stimuli. Half of the nouns were of masculine or neuter gender. Forty letter strings were written with wide and 40 with narrow spacing between the letters.

\subsection{Procedure}

Subjects were randomly assigned to two experimental groups, with sex being balanced within and between the groups. Subjects in one group performed a word category decision task (WC) together with a baseline (BASE) 
task. The other group completed a gender decision task (GEN) and BASE. In WC, subjects were presented with the prepositions and the masculine nouns, and made a word category decision via button press. In GEN, subjects decided whether the gender of the 160 nouns was masculine or neuter. In BASE, all subjects decided whether the consonant letter strings were written with wide or narrow spacing. All items and tasks were applied in pseudo-randomised order. In each trial, subjects were precued for $500 \mathrm{~ms}$ which task to perform. After a fixation period of $500 \mathrm{~ms}$, the written stimulus appeared in the centre of a computer screen for $500 \mathrm{~ms}$, followed by a fixation period of $8.5 \mathrm{~s}$ in which the response was made. To ensure subjects were attentive during fixation, in $10 \%$ of the trials evenly distributed across items, the fixation cross changed its colour randomly during the interstimulus-interval. Participants were instructed to respond as quickly as possible to these changes. Because of possible interferences of this additional task with the experimental tasks, these trials were excluded from further analyses (cf. Friederici et al., 2000b).

\section{Data acquisition and analysis}

\subsection{Behavioural data}

Reaction times (RT) and response accuracy (error rates, ER) were registered during the experiment. RT and ER were analysed separately using repeated measures ANOVAs with "Group" (WC vs. GEN) as between subject factor and "Condition" (experimental trials vs. BASE) as within-subject factor. The direct contrast between WC and GEN was assessed using a two-sample $t$ test.

\subsection{Imaging data}

The experiment was carried out on a 3T scanner (Medspec 30/100, Bruker, Ettlingen). A standard birdcage head coil was used. Visual stimuli were presented on a screen positioned at the head end of the magnet bore. Subjects viewed the screen through mirror glasses. Cushions and stereotactic fixation were used to reduce head motion. T1-weighted MDEFT (Ugurbil et al., 1993) images (data matrix $256 \times 256$, TR $1.3 \mathrm{~s}$, TE $10 \mathrm{~ms}$ ) were obtained with a non-slice-selective inversion pulse followed by a single excitation of each slice (Norris, 2000). For registration purposes, a set of T1weighted EPI images were taken with a TE $30 \mathrm{~ms}$, flip angle $90^{\circ}$, acquisition bandwidth $100 \mathrm{kHz}$. The inversion time was $1200 \mathrm{~ms}$, with a TR of $45 \mathrm{~s}$ and four averages. The functional data were recorded using a gradient-echo EPI sequence with a TE $30 \mathrm{~ms}$, flip angle $90^{\circ}$, TR $1 \mathrm{~s}$, acquisition bandwidth $100 \mathrm{kHz}$. The matrix acquired was $64 \times 64$ with a FOV of $19.2 \mathrm{~cm}$, resulting in an in- plane resolution of $3 \mathrm{~mm} \times 3 \mathrm{~mm}$. Eight axial slices were recorded ( $5 \mathrm{~mm}$ thickness, $2 \mathrm{~mm}$ skip). The data processing was performed using the software package LIPSIA (Lohmann et al., 2001). Functional data were corrected for motion using a matching metric based on linear correlation. To correct for the temporal offset between the slices acquired in one scan, a sinc-interpolation based on the Nyquist-Shannon-Theorem was applied. A temporal high-pass filter with a cut-off frequency of $1 / 60 \mathrm{~Hz}$ was used for baseline correction of the signal and a spatial Gaussian filter with FWHM =5 $.64 \mathrm{~mm}$ was applied. The increased auto-correlation due to filtering was taken into account during statistical evaluation. To align the functional data slices with a 3D stereotactic co-ordinate reference system, a rigid linear registration with six degrees of freedom (3 rotational and 3 translational) was performed.

The transformation parameters were estimated on the basis of the MDEFT and EPI-T1 images with respect to an individual 3D reference data set. This 3D data set was acquired for each subject during a separate session. Subsequently, the transformation matrix was linearly scaled to standard size. Using these parameters the individual 2D data sets were transformed into a 3D stereotactic space (Talairach \& Tournoux, 1988).

The statistical evaluation was based on a least-squares estimation using the general linear model for serially auto-correlated observations (Friston, 1994; Friston et al., 1995a, 1995b; Worsley \& Friston, 1995). The design matrix was generated with a synthetic haemodynamic response function (Friston et al., 1998; Josephs, Turner, $\&$ Friston, 1997). The model equation, including the observation data, the design matrix, and the error term, was convolved with a Gaussian kernel of 4s FWHM dispersion. The model includes an estimate of temporal auto-correlation that is used to estimate the effective degrees of freedom. One basic function for each subset of items (WC: nouns vs. prepositions; GEN: masculine vs. neuter; BASE) was specified in the design matrix. For each subject the direct contrast "WC-BASE" or "GEN-BASE" was computed. Group analyses were performed applying a Gaussian test for the 3D contrast images (Bosch, 2000). A two-sample $t$ test was administered to detect differences between the two syntactic tasks. Moreover, a conjunction analysis (Price \& Friston, 1997; Price, Moore, \& Friston, 1997) using the contrast "(WC-BASE) + (GEN-BASE)" was carried out to assess common brain structures active in both processes.

\section{Results}

\subsection{Behavioural data}

For the reaction time data (RT), an ANOVA yielded a significant main effect for group (WC vs. GEN: 
$F_{1,16}=10.35, p=.005$ ) and condition (syntactic vs. BASE: $F_{1.16}=14.58, p=.002$ ), and a significant interaction $\left(F_{1,16}=14.58, p=.006\right)$. The subsequent twosample $t$ test for the syntactic tasks revealed significantly faster responses for WC than GEN $\left(t_{16}=4.32\right.$, $p=.001)$. For the error rates, there were no significant effects in the ANOVA (Table 1).

\subsection{Imaging data}

In the direct contrast WC-BASE, the inferior tip of BA 44 as well as the left BA 47 were activated in the left inferior frontal gyrus (IFG). In the right IFG, there was activation in the superior BA 44. Further activation foci were located in the left superior frontal gyrus (SFG), cingulate gyrus (GC), and in the head of the left caudate

Table 1

Mean reaction times, error rates, and SD (in parentheses) as a function of syntactic task (GEN, gender decision and WC, word category decision)

\begin{tabular}{llllll}
\hline & \multicolumn{2}{l}{ Reaction times $(\mathrm{ms})$} & & \multicolumn{2}{l}{ Error rates $(\%)$} \\
\cline { 2 - 3 } \cline { 5 - 6 } & GEN & WC & & GEN & WC \\
\hline Baseline & 930 & 750 & & 12.7 & 9.2 \\
\multirow{3}{*}{ Experimental } & $(174)$ & $(177)$ & & $(25.6)$ & $(11.3)$ \\
& 1059 & 762 & & 3.2 & 11.4 \\
& $(147)$ & $(142)$ & & $(2.3)$ & $(30.8)$ \\
\hline
\end{tabular}

nucleus $(Z>3.09, p<.001$, uncorrected; Fig. 1a and Table 2). The contrast GEN-BASE revealed only activation of the left SFG, but no activations in the left IFG at threshold of $Z>3.09$ ( $p<.001$, uncorrected). At a more lenient threshold $(Z=2.48, p<.007$, uncorrected), activation was also observed in the inferior tip of BA 44 and the left BA 45 (Fig. $1 \mathrm{~b}$ and Table 2). In the two-sample $t$ test, however, none of these regions differed significantly between the tasks. In a conjunction analysis conducted to reveal common brain areas active in both tasks, the main focus of activation was located in the inferior tip of BA $44(Z>3.09, p<.001$, uncorrected; Fig. 1c and Table 2). In addition, there were two local maxima in the left BA 45 and BA 47 (corresponding to the activation foci in each syntactic condition) and in the left SFG and GC (Table 2).

\section{Discussion}

The behavioural and neural correlates of two different types of syntactic information (word category [WC] vs. gender [GEN]) were investigated. In accordance with the syntax-first models of language comprehension (Frazier, 1987; Friederici, 1995) which assume primacy of WC information processing, it was shown that the reaction times for WC decision are faster that for GEN decision. A similar difference was also observed for the

Table 2

Mean $Z$-scores of regions of interest (ROI) in the left hemisphere for the contrast of each syntactic task vs. baseline and the conjunction analysis of both syntactic tasks

\begin{tabular}{|c|c|c|c|c|c|}
\hline \multicolumn{6}{|c|}{ Talairach-coordinates } \\
\hline Structure & Brodmann's area & $x$ & $y$ & $z$ & Mean $Z$-score \\
\hline \multicolumn{6}{|c|}{ Word category decision minus baseline } \\
\hline \multirow[t]{4}{*}{ L IFG } & 44 & -50 & 17 & 8 & 4.1 \\
\hline & 44 & -47 & 11 & 17 & 3.3 \\
\hline & 47 & -44 & 20 & -2 & 3.7 \\
\hline & 47 & -34 & 29 & -5 & 4.2 \\
\hline \multirow[t]{2}{*}{ R IFG } & $44 / 6$ & 46 & 11 & 23 & 3.9 \\
\hline & 44 & 36 & 14 & 26 & 3.3 \\
\hline L SFG & 10 & -8 & 55 & 11 & 3.1 \\
\hline \multirow[t]{2}{*}{$\mathrm{L} \mathrm{GC}$} & 32 & -8 & 41 & -5 & 3.8 \\
\hline & 30 & -2 & -50 & 17 & 3.6 \\
\hline $\mathrm{L} \mathrm{CH}$ & & -5 & 11 & 8 & 3.8 \\
\hline \multicolumn{6}{|c|}{ Gender decision minus baseline } \\
\hline \multirow[t]{2}{*}{ L IFG } & 44 & -47 & 20 & 8 & 2.5 \\
\hline & 45 & -47 & 23 & 2 & 2.6 \\
\hline L SFG & 10 & -5 & 58 & 14 & 3.4 \\
\hline \multicolumn{6}{|c|}{ Conjunction analysis } \\
\hline \multirow[t]{4}{*}{ L IFG } & 44 & -50 & 17 & 8 & 6.1 \\
\hline & 44 & -44 & 11 & 20 & 3.8 \\
\hline & 45 & -47 & 26 & 2 & 4.7 \\
\hline & 47 & -44 & 23 & 0 & 5.0 \\
\hline L SFG & $9 / 10$ & -8 & 58 & 11 & 4.9 \\
\hline $\mathrm{L}$ GC & 25 & -5 & 17 & -5 & 4.3 \\
\hline
\end{tabular}

Abbreviations used: L, left; R, right; IFG, inferior frontal gyrus; SFG, superior frontal gyrus; GC, gyrus cingulate; $\mathrm{CH}$, caudate head. 
(a) WC - BASE

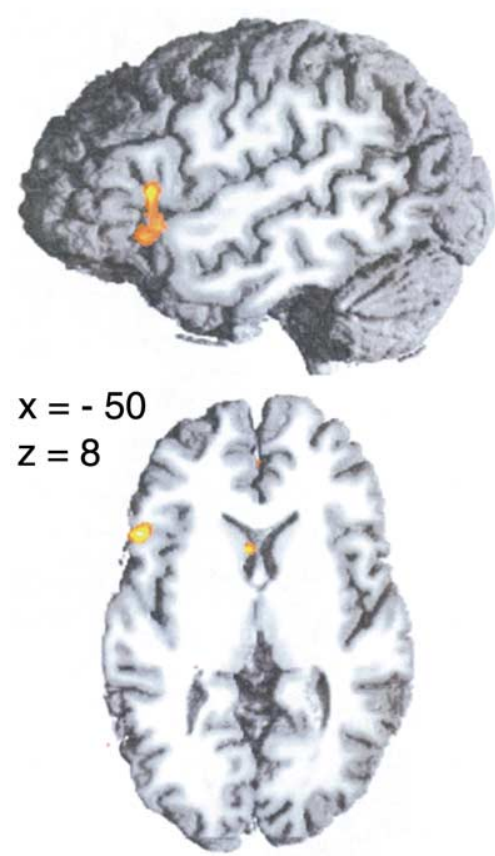

3

4.1 (b) GEN - BASE

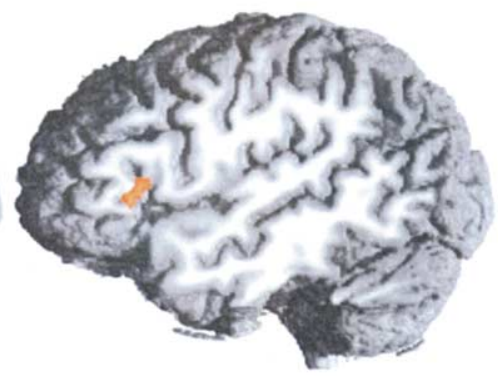

$x=-47$

$z=8$

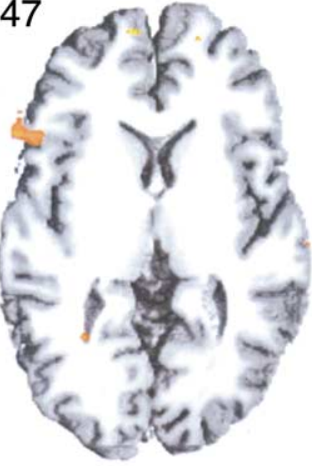

2.3

3.3 (c) Conjunction
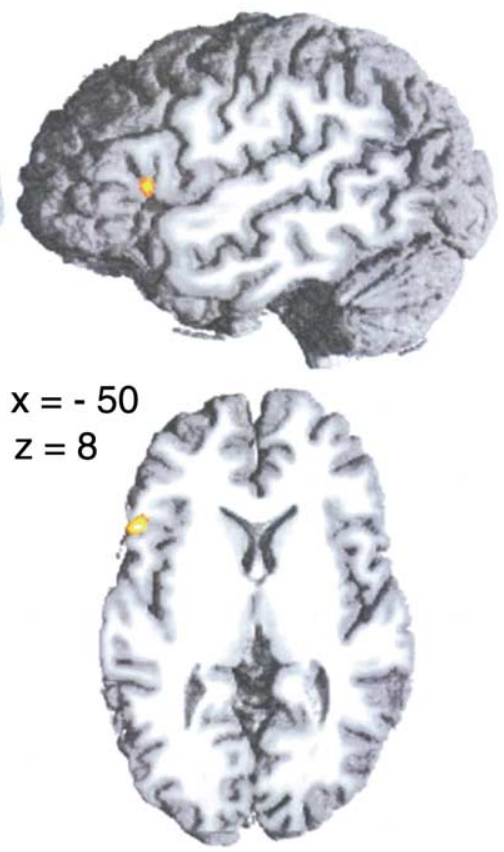

5

6.1

Fig. 1. Statistical parametric maps (SPM $\{z\}$ ) of the activations in the experimental contrasts, superimposed onto a high-resolution 3D MDEFT scan of a representative individual brain. The co-ordinates of each particular section in the sagittal slices (top row) and the transaxial slices (bottom row) is indicated by the corresponding $x$ - and $z$-values in Talairach co-ordinate space. The coloured scale bars indicate the activation strength. (For a complete list of activations cf. Table 2.) (a) Word category decision minus baseline; (b) gender decision minus baseline; (c) conjunction analysis: common activation in both syntactic tasks minus baseline. (Note that for optimal display of the activation maxima, different thresholds have been chosen for the $Z$-values in each contrast.)

baseline task which indicates that the experimental task affected the baseline task in latency. However, no difference was observed for the error rates which suggests that both syntactic decisions are equally difficult.

The pattern found for the imaging data is very straightforward. The inferior tip of BA 44 is activated in both syntactic tasks and in the conjunction analysis. One might argue that this effect represents phonological or semantic processes in addition to syntactic processes since none of these processes had been controlled for in a separate baseline task. However, neither phonological nor semantic processes are likely to evoke the observed pattern, as suggested by previous studies (Démonet et al., 1992; Gabrieli, Poldrack, \& Desmond, 1998; Poldrack et al., 1999; Thompson-Schill et al., 1997; Zatorre, Evans, Meyer, \& Gjedde, 1992; Zatorre, Meyer, Gjedde, \& Evans, 1996). First, Friederici et al. (2000b) were able to differentiate between semantic and syntactic processing (using the same WC task that was used here), and the activations presented in the present study are a precise replication of the former WC data. Second, as several imaging studies have shown, phonological processing is supported by the superior portion of Broca's area rather than its inferior tip (Démonet et al., 1992; Heim, Opitz,
Jescheniak, \& Friederici, 2001; Zatorre et al., 1992, 1996). Therefore, the present effect is likely to be attributed to syntactic processing.

In the task-specific analyses, an additional focus of activation was found for each of the different tasks in the left IFG. Activation in addition to BA 44 was found in BA 45 for GEN while an additional focus was observed in BA 47 for WC. These regions have been reported in a number of studies for semantic processes (Beauregard et al., 1997; Poldrack et al., 1999; Vandenberghe, Price, Wise, Josephs, \& Frackowiak, 1996). The data available in the literature on semantic processing do not allow any conclusion to be drawn about a further functional subdivision of the anterior IFG with respect to different aspects of semantic processes.

Interestingly, it is certain that the two syntactic processes that activated those different spots in BA 45 and BA 47 are clearly functionally distinct in the scope of psycholinguistic theory. Although both word category information and gender information are part of the lemma (Levelt, Roelofs, \& Meyer, 1999), the two information types serve different functions during language comprehension. Word category is formal information that allows the listener to build up the local 
syntactic structure when hearing or reading a sentence (Frazier, 1987). Gender information, in contrast, is relevant in establishing antecedent relations (e.g., between a pronoun and an antecedent noun) as for example in Spanish, French, Italian, or German (De Vincenzi, 1999), or agreement between different constituents (e.g., subject and verb as for example in Hebrew: Deutsch \& Bentin, 2001). Moreover, in the domain of gender information, there is at least a partial overlap between grammatical and natural gender. In so far, gender information may be closer connected to lexical-semantic content while word category information is linked to formal aspects. Along these lines, one might assume that WC and GEN co-activate different structures in the lexical-semantic network in the more anterior IFG activations in addition to BA 44

\section{Conclusion}

The present results show that the inferior tip of BA 44 as part of Broca's area is a module responsible for the processing of different types of syntactic information during language comprehension. However, it is known that Broca's area also contributes to the processing of musical sequences (Maess, Kölsch, Gunter, \& Friederici, 2001), the perception of the rhythm of motion (Schubotz $\&$ von Cramon, 2001), and the imagery of motion (Binkofski et al., 2000) in different contexts. The present data may thus suggest that BA 44 as part of Broca's area receives its functional specification by its particular interaction within different neural networks. Here, we have identified two such networks for distinct aspects of syntactic processing.

\section{References}

Amunts, K., Schleicher, A., Bürgel, U., Mohlberg, H., Uylings, H. B. M., \& Zilles, K. (1999). Broca's region re-visited: Cytoarchitecture and intersubject variability. The Journal of Comparative Neurology, 412, 319-341.

Beauregard, M., Chertkow, H., Bub, D., Murtha, S., Dixon, R., \& Evans, A. (1997). The neural substrate for concrete, abstract, and emotional word lexica: A positron emission tomography study. Journal of Cognitive Neuroscience, 9, 441-461.

Binkofski, F., Amunts, K., Stephan, K. M., Posse, S., Schormann, T. Freund, H. J., Zilles, K., \& Seitz, R. J. (2000). Broca's region subserves imagery of motion: A combined cytoarchitectonic and fMRI study. Human Brain Mapping, 11, 273-285.

Bosch, V. (2000). Statistical analysis of multi-subject fMRI data: The assessment of focal activations. Journal of Magnetic Resonance Imaging, 11, 61-64.

Broca, P. (1861). Remarques sur la siège de la faculté de langage articulé, suivies d'une observation d'aphemie. Bulletin des Societés Anatomiques de Paris, 2, 330-357.

Brodmann, K. (1909). Vergleichende Lokalisationslehre der Großhirnrinde in ihren Prinzipien dargestellt auf Grund des Zellenbaus. Leipzig: Johann Ambrosius Barth Verlag.
Caplan, D., Alpert, N., \& Waters, G. (1998). Effects of syntactic structure and propositional number on patterns of regional cerebral blood flow. Journal of Cognitive Neuroscience, 10, 541552.

Caplan, D., Alpert, N., \& Waters, G. (1999). PET studies of syntactic processing with auditory sentence presentation. Neuroimage, 9, 343-351.

Caplan, D., Alpert, N., Waters, G., \& Olivieri, A. (2000). Activation in Broca's area by syntactic processing under conditions of concurrent articulation. Human Brain Mapping, 9, 65-71.

De Vincenzi, M. (1999). Differences between the morphology of gender and number: Evidence from establishing coreferences. Journal of Psycholinguistic Research, 28, 537-555.

Démonet, J.-F., Chollet, F., Ramsay, S., Cardebat, D., Nespoulous, J.L., Wise, R., Rascol, A., \& Frackowiak, R. (1992). The anatomy of phonological and semantic processing in normal subjects. Brain, $115,1753-1768$.

Desmond, J. E., Sum, J. M., Wagner, A. D., Demb, J. B., Shear, P. K., Glover, G. H., Gabrieli, J. D. E., \& Morrell, M. J. (1995). Functional MRI measurement of language lateralization in Wadatested patients. Brain, 118, 1411-1419.

Deutsch, A., \& Bentin, S. (2001). Syntactic and semantic factors in processing gender agreement in hebrew: Evidence from ERPS and eye movement. Journal of Memory and Language, 45, 200224

Fiebach, C., Schlesewsky, M., \& Friederici, A. D. (2001). Syntactic working memory and the establishment of filler-gap dependencies: Insights from ERPs and fMRI. Journal of Psycholinguistic Research, 30, 321-338.

Frazier, L. (1987). Theories of sentence processing. In J. Garfield (Ed.), Modularity of knowledge representation and natural-language processing. Cambridge, Massachusetts: MIT Press.

Friederici, A. D. (2002). A neural basis of sentence processing. Trends in Cognitive Sciences, 6, 78-84.

Friederici, A. D. (1995). The time course of syntactic activation during language processing: A model based on neuropsychological and neurophysiological data. Brain and Language, 50, 259-281.

Friederici, A. D., Meyer, M., \& von Cramon, D. Y. (2000a). Auditory language comprehension: An event-related fMRI study on the processing of syntactic and lexical information. Brain and Language, 74, 289-300.

Friederici, A. D., Opitz, B., \& von Cramon, D. Y. (2000b). Segregating semantic and syntactic aspects of processing in the human brain: A fMRI investigation of different word types. Cerebral Cortex, 10, 698-705.

Friston, K. J. (1994). Statistical parametric mapping. In R. W. Thatcher, M. Hallet, T. Zeffiro, E. R. John, \& M. Huerta (Eds.), Functional imaging (pp. 79-93). San Diego: Academic Press.

Friston, K. J., Holmes, A. P., Poline, J.-B., Grasby, B. J., Williams, C. R., Frackowiak, R. S. J., \& Turner, R. (1995a). Analysis of fMRI time-series revisited. Neuroimage, 2, 45-53.

Friston, K. J., Holmes, A. P., Poline, J.-B., Grasby, B. J., Williams, C. R., Frackowiak, R. S. J., \& Turner, R. (1995b). Statistical parametric maps in functional imaging: A general linear approach. Human Brain Mapping, 2, 189-210.

Friston, K. J., Fletcher, P., Josephs, O., Holmes, A., Rugg, M. D., \& Turner, R. (1998). Event-related fMRI: Characterizing differential responses. Neuroimage, 7, 30-40.

Gabrieli, J. D. E., Desmond, J. E., Demb, J. B., Wagner, A. D., Stone, M. V., Vaidya, C. J., \& Glover, G. H. (1996). Functional magnetic resonance imaging of semantic memory processes in the frontal lobes. Psychological Science, 7, 278-283.

Gabrieli, J. D. E., Poldrack, R. A., \& Desmond, J. E. (1998). The role of left prefrontal cortex in language and memory. Proceedings of the National Academy of Sciences USA, 95, 906-913.

Grossman, M., Zurif, E., Lee, C., Prather, P., Kalmanson, J., Stern, M. B., \& Hurtig, H. I. (2002). Information processing speed and 
sentence comprehension in Parkinson's disease. Neuropsychology, 16, 171-174.

Gunter, T. C., Friederici, A. D., \& Schriefers, H. (2000). Syntactic gender and semantic expectancy: ERPs reveal early autonomy and late interaction. Journal of Cognitive Neuroscience, 12, 556-568.

Grodzinsky, Y. (2000). The neurology of syntax: Language use without Broca's area. Behavioral and Brain Sciences, 23, 1-71.

Hahne, A., \& Friederici, A. D. (2002). Differential task effects on semantic and syntactic processes as revealed by ERPs. Cognitive Brain Research, 13, 339-356.

Heim, S., Opitz, B., Jescheniak, J. D., \& Friederici, A. D. (2001). Die funktionelle Neuroanatomie von Syntax und Phonologie bei der Sprachproduktion. In A. Zimmer, K. Lnage, K.-H. Bäuml, R. Loose, R. Scheuchenpflug, O. Tucha, H. Schnell, \& R. Findl (Eds.), Experimentelle Psychologie (p. 52). Lengerich: Pabst.

Josephs, O., Turner, R., \& Friston, K. (1997). Event-related fMRI. Human Brain Mapping, 5, 243-248.

Just, M. A., Carpenter, P. A., Keller, T. A., Eddy, W. F., \& Thulborn, K. R. (1996). Brain activation modulated by sentence comprehension. Science, 274, 114-116.

Levelt, W. J. M., Roelofs, A., \& Meyer, A. S. (1999). A theory of lexical access in speech production. Behavioral and Brain Sciences, $22,1-75$.

Lohmann, G., Müller, K., Bosch, V., Mentzel, H., Hessler, S., Chen, L., \& von Cramon, D. Y. (2001). Lipsia-A new software system for the evaluation of functional magnetic resonance images of the human brain. Computerized Medical Imaging and Graphics, 25, 449-457.

Maess, B., Kölsch, S., Gunter, T. C., \& Friederici, A. D. (2001). Musical syntax is processes in Broca's area: an MEG study. Nature Neuroscience, 4, 540-545.

Moro, A., Tettamanti, M., Perani, D., Donati, C., Cappa, S. F., \& Fazio, F. (2001). Syntax and the brain: Disentangling grammar by selective anomalies. Neuroimage, 13, 110-118.

Nobre, A. C., Price, C. J., Turner, R., \& Friston, K. (1997). Selective processing of nouns and functions words in the human brain. Neuroimage, 5, 53.

Norris, D. G. (2000). Reduced power multi-slice MDEFT imaging. Journal of Magnetic Resonance Imaging, 11, 445-451.

Perani, D., Cappa, S. F., Schnur, T., Tettamanti, M., Collina, S., Rosa, M. M., \& Fazio, F. (1999). The neural correlates of verb and noun processing. A PET study. Brain, 122, 2337-2344.

Poldrack, R. A., Wagner, A. D., Prull, M. W., Desmond, J. E., Glover, G. H., \& Gabrieli, J. D. E. (1999). Functional specialization for semantic and phonological processing in the left inferior prefrontal cortex. Neuroimage, 10, 15-35.
Price, C. J., \& Friston, K. J. (1997). Cognitive conjunction: A new approach to brain activation experiments. Neuroimage, 5, 261270.

Price, C. J., Moore, C. J., \& Friston, K. J. (1997). Subtractions, conjunctions, and interactions in experimental design of activation studies. Human Brain Mapping, 5, 264-272.

Schubotz, R. I., \& von Cramon, D. Y. (2001). Interval and ordinal properties of sequences are associated with distinct premotor areas. Cerebral Cortex, 11, 210-222.

Stromswold, K., Caplan, D., Alpert, N., \& Rauch, S. (1996). Localization of syntactic comprehension by positron emission tomography. Brain and Language, 52, 452-473.

Talairach, P., \& Tournoux, J. (1988). A stereotactic coplanar atlas of the human brain. Stuttgart: Thieme.

Thompson-Schill, S. L., D'Esposito, M., Aguirre, G. K., \& Farah, M. J. (1997). Role of left inferior prefrontal cortex in retrieval of semantic knowledge: A reevaluation. Proceedings of the National Academy of Sciences USA, 94, 14792-14797.

Ugurbil, K., Garwood, M., Ellermann, J., Hendrich, K., Hinke, R., Hu, X., Kim, S.-G., Menon, R., Merkle, H., Ogawa, S., \& Salmi, R. (1993). Imaging at high magnetic fields: Initial experiences at 4T. Magnetic Resonance Quarterly, 9, 259.

Vandenberghe, R., Price, C., Wise, R., Josephs, O., \& Frackowiak, R. S. J. (1996). Functional anatomy of a common semantic system for words and pictures. Nature, 383, 254-256.

Worsley, K. J., \& Friston, K. J. (1995). Analysis of fMRI time-series revisited-again. Neuroimage, 2, 359-365.

Zatorre, R. J., Evans, A. C., Meyer, E., \& Gjedde, A. (1992). Lateralization of phonetic and pitch discrimination in speech processing. Science, 256, 846-849.

Zatorre, R. J., Meyer, E., Gjedde, A., \& Evans, A. C. (1996). PET studies of phonetic processing in speech: Review, replication, and reanalysis. Cerebral Cortex, 6, 21-30.

\section{Further reading}

Berndt, R., \& Caramazza, A. (1980). A redefinition of the syndrome of Broca's aphasia. Applied Psycholinguistics, 1, 225-278.

Demb, J. B., Desmond, J. E., Wagner, A. D., Vaidya, C. J., Glover, G. H., \& Gabrieli, J. D. E. (1995). Semantic encoding and retrieval in the left inferior prefrontal cortex: A functional MRI study of task difficulty and process specificity. The Journal of Neuroscience, 15, $5870-5878$. 